Mauro Wilton de Sousa ${ }^{1}$

\title{
Recepção Mediatica e Novos Media: Rearticulações práticas e conceituais
}

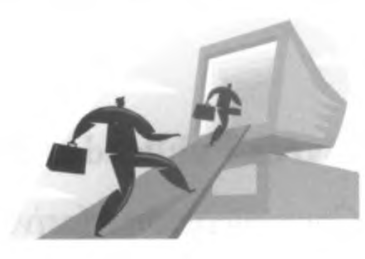

\section{Resumo}

A presença generalizada de novos meios de comunicação nas praticas de vida das pessoas bem como o reconhecimento da simultaneidade de mutações acontecendo no sistema social mais amplo se colocam como duas mediações contextuais importantes no campo de estudos tradicionalmente denominado de recepção mediatica. O presente texto desenvolve indagações iniciais a respeito dessas mediações sugerindo que processos de mutação acontecendo nesses dois contextos sinalizam também sobre rearticulações conceituais possíveis no âmbito dos estudos sobre recepção mediática em seu objeto e em sua atualidade.

\section{Introdução}

Os estudos sobre a relação entre as pessoas e os meios de comunicação se constituíram desde o século passado sob a denominação de recepção mediática. Sob essa ótica toda uma tradição de estudos desde então se desenvolveu, sobretudo a partir dos estudos norte-americanos. Objetos de estudo semelhantes foram trabalhados em outros contextos disciplinares e em outros continentes, como os estudos europeus sobre os usos sociais da comunicação, ou os estudos sobre a genealogia das práticas culturais de leitura de textos, desenvolvidos sobretudo a partir da Ecóle des Annales (Belisle, 1992).

O contexto desses estudos, especialmente na tradição norteamericana e que se tornou hegemônica, trouxe sem dúvida suas marcas: o desenvolvimento tecnológico derivado da revolução industrial se manifestava nas possibilidades de ferramentas inovadoras e de grande alcance social, como a imprensa, o cinema e mais tarde o rádio e a televisão. $\mathrm{O}$ contexto urbano e industrial então em consolidação foi um campo oportuno para a criação da sociedade do consumo massificado e generalizado. O capitalismo urbano industrial encontrava então

(1) Mauro Wilton de Sousa, pesquisador e professor junto ao Departamento de Cinema, Rádio e Televisão da Escola de Comunicações e Artes da USP. todas as condições de maturação e de expansão. Reproduziu-se por completo na verticalidade da relação emissor-receptor a verticalidade da relação sistêmica entre produção-consumo. O processo social da comunicação que então se construiu reproduziu e ao mesmo tempo alimentou o sistema social que lhe dava contexto. Meios de comunicação e desenvolvimento social se uniram na peculiaridade de manifestação histórica da modernidade capitalista tanto quan- 
to experimentavam as conseqüências econômicas, sociais e culturais desse processo mais amplo denominado de sociedade do consumo. Técnica e sociedade pareceram mutuamente se explicarem.

O presente texto parte do reconhecimento, já antigo e por demais debatido, de que os estudos que desde então se desenvolveram a respeito mostram-se hoje com limitações. (Marcondes Filho, 1990. pag. 59; Martin-Barbero, 1995.pag. 39). Há um novo contexto de desenvolvimento tecnológico, com múltiplas ferramentas, estratégias e dispositivos de usos cada vez mais generalizados. Temas e questões como a emergência da sociedade pós industrial, a mundialização da cultura e a globalização da economia sinalizam que há um processo social mais amplo em mutação e que se manifesta nas práticas de vida cotidiana individual e coletiva.

Em síntese, há indicadores de uma sociedade em trânsito acelerado nos dias atuais e o processo da comunicação faz parte desse mesmo contexto. Um processo que envolve a mediação de diferentes media mas não se atém a eles como aconteceu no passado, busca entende-los não como fim em si mesmos mas como mediação na relação entre indivíduo e sociedade. As reflexões a seguir apontam, mais do que aprofundam, alguns aspectos desse cenário em mutação. Cenário entre técnica e sociedade, em que o processo da comunicação o reflete, ontem como hoje, importando mais do que reconhecê-lo, qualificá-lo.

\section{Técnica e sociedade: entre determinações e mediações}

A relação entre técnica e comunicação se apoia desde sempre na relação entre técnica e sociedade. Não é difícil reconhecer nos dias atuais a presença da técnica em todos os campos do conhecimento e da atividade humana. Qualificar essa presença se coloca como uma questão de debates intensos, e que permeiam tanto a filosofia quanto a ciência. Já em sua concepção como ferramenta ela tem como constitutivo a instrumentalidade na transformação de objetos. As razões sociais de seu uso, o discurso que a motiva em seu uso científico e estético, faz dela o que se denomina como tecnologia. Se a dimensão de instrumentalidade é pois inerente à técnica, está aí a matriz do porque ao se constituir como tecnologia carrega um potencial político, a possibilidade de atuação e transformação na esfera material e objetiva, tanto quanto na esfera de valores culturais e ideológicos. Surge então a questão que se reporta ao seu lugar de determinação ou de mediação, não só na esfera da produção econômica, mas em todas as dimensões onde se insere pelas ferramentas que lhe dão suporte. (Heidegger, 2002; Lemos, 2002; Rüdiger, 2006; Miege, 2007).

Essa questão ocupa o conhecimento filosófico tanto quanto o científico há séculos e tem sido longamente debatida especialmente desde o advento da revolução industrial. É uma questão que se associou como nunca à consolidação de uma racionalidade que desde séculos anteriores historicamente se defi- 
nia e se desenvolvia e que ainda hoje lhe dá contexto e condições valorativas: a modernidade capitalista.

Se as ciências sociais tanto quanto a filosofia desde então se debruçaram na compreensão da emergência desse processo, hoje tantos outros estudiosos se aplicam na compreensão do cenário de transformações e mutações que se desenvolveu entre técnica e sociedade.

Atente-se como é instigante nos dias atuais afirmações como a de Couchot $(2003,158)$ quando assinala no estudo da imagem numérica que técnica e ciência assumem hoje uma importância cada vez mais decisiva sobre a arte, campo da tecnociência, e que nesse contexto o sujeito não é mais aparelhado a uma mecânica material, mas a linguagens programáticas ..."onde o numérico intima o sujeito a se redefinir”. O lugar da técnica se desloca em sua instrumentalidade, assumindo um lugar interpelador.

Esta observação é semelhante à que Bruno assinala na relação entre tecnologias cognitivas e espaços do pensamento:

"... a técnica é hoje um dos agentes privilegiados de problematização do pensamento. Somos de tal modo interpelados pela tecnologia que já não podemos refletir sobre ela sem questionar, com um mesmo movimento, o que é homem e o que é pensamento" (2003, pag. 212).

Esses deslocamentos quanto ao lugar de atuação da técnica, de uma instrumentalidade objeto passando para uma possibilidade interpeladora, na verdade são questões presentes na contemporaneidade de tantos outros objetos de estudo ou mesmo de indagações como nas perspectivas advindas do ciberespaço, do mundo virtual, da biopolítica e do pós-humano, da tecnociência. São perspectivas que inclusive se reportam a questionamentos sobre o eixo que historicamente tem orientado na filosofia as possibilidades de produção do conhecimento enquanto sujeito-objeto, e que agora influenciado pelos muitos e múltiplos processos técnicos que também o envolvem, motiva a afirmação de que seria melhor denominá-los de quase-sujeito e de quase-objeto. (apud Bruno, 2003, pág. 208).

Se o lugar da técnica se configura em mudança em todos os âmbitos onde se insere, o mesmo se dá na compreensão da modernidade capitalista que marca o contexto estruturante do sistema social contemporâneo. Termos como crise, mudanças, mutações e rupturas têm sido utilizados para sinalizar que a racionalidade que sustentou a modernidade, a relação meio-fins, a dimensão do tempo assumida na perspectiva de progresso, tanto quanto a consolidação de uma organização social desde instituições mantenedoras e indicadoras do devir começam a ser questionadas. A racionalidade que sustentou razão e técnica e as perspectivas da liberdade, da igualdade e da 
fraternidade não estariam mais iluminando as utopias sociais, ao contrario, propiciariam hoje um movimento para o presente, para uma liberdade que não se move para o social distante, mas para o individual ativo e presente no tempo cotidiano. As utopias se reinventam para o tempo presente. Traços valorativos como esses acabam apontando que o âmbito da mutação não se envolve de imediato numa dimensão revolucionaria da estrutura de produção e consumo da modernidade capitalista, mas nas formas e condições de suas manifestações e proposições valorativas, âmbito das práticas culturais e políticas, tanto quanto das formas de se conceber e viver a vida. Expressões como modernidade tardia ou pós-modernidade, entre outras, indicariam esse processo de mudança onde a presença da técnica seria determinante das condições de produção como de aplicação e uso dos valores e perspectivas que se delineiam no âmbito da cultura. Esta é uma tese que encontra opositores propondo a existência de múltiplas mediações, mais do que só e apenas determinações causais, entre técnica e sociedade e cuja manifestação e significação importa analisar no contexto histórico onde se dão.

Este é o elemento nuclear do debate, ou seja, a qualificação dos nexos que historicamente colocaram a técnica e seus desdobramentos no âmbito da tecnologia como determinação ou como mediação na construção das práticas sociais.

O campo da comunicação social se insere nesse cenário e o espelha de uma forma muito próxima. O reconhecimento da atualidade e da significação do processo da comunicação na sociedade contemporânea tem também propiciado a observação crítica de que cada vez mais acentua-se um processo de midiatização da vida social, política e cultural, ou seja, a centralidade da comunicação mediada por tecnologias tem lhe dado papel fundamental na compreensão da própria sociedade. $\mathrm{O}$ processo da comunicação mediada por técnicas, ferramentas e dispositivos os mais diversos ultrapassando o tempo apenas definido pelos meios massivos se estendeu e generalizou propiciando a midiatização da sociedade nos dias atuais. A presença da técnica seria hegemônica dado especialmente o poder que lhe é atribuído em seu uso. (Rüdiger, 2003; Miège, 2007).

Essas observações envolvem na verdade questões diversas mas desde uma argumentação que sinaliza que a técnica ao dar suporte aos meios de comunicação e de informação, e estes ao se expandirem e chegarem ao processo contemporâneo da midiatização, estariam construindo uma determinação do papel da técnica na construção dos valores que vêm sustentando a configuração da sociedade contemporânea, e, como tal, reproduziria os interesses do sistema sócio-economico. Termos e processos sob a denominação de comunicação mediatica, midiatização, centralidade da comunicação, sociedade da informação e da comunicação sinalizariam no âmbito da comunicação diferentes processos onde essa tendência de determinação social da técnica se expressa. 
Por outro lado, no questionamento dessa perspectiva, advoga-se que a sociedade como um todo perpassa processos históricos de mutação com múltiplas outras determinações, para além das ferramentas técnicas, com implicações valorativas que se associam à própria estrutura da vida social. Houve e há um contexto social sistêmico baseado em valores e causas, objetivos e fins e que secundou, abrigou ou de alguma forma é determinante, enquanto sistema mais amplo e estrutural, das praticas e processos que visualizaram e possibilitaram o encaminhamento da relação entre meios de comunicação e sociedade. Se são meios então se envolvem em fins, e estes se encontram no próprio sistema social. Afinal, o processo da globalização da economia e o da mundialização da cultura, tanto quanto a hegemonia e atualização constante das formas de estruturação e manutenção vitoriosa do capital não são fatos, valores e contextos estranhos a uma temporalidade da sociedade atual e muito menos da comunicação e de seus suportes e interesses. Não há neutralidade ou nudez político e ideológica também em comunicação. A técnica também em comunicação reflete esse mesmo contexto, não se explica em si mesma.

Atente-se que esse debate leva à constatação da dificuldade de uma determinação linear da técnica sobre a sociedade ou o seu oposto. A perspectiva de qualificar esse processo entre técnica e sociedade mais pelas mediações que o envolvem do que pelas suas possíveis determinações parece dar conta dessa tensão pela capacidade de se colocar no tempo e no espaço histórico de mutações e circunstancias que acompanham a técnica e a sociedade em seus processos de desenvolvimento. Mediações presentes muitas vezes nos próprios atores e em suas diferentes condições e contextos, como assinala Willians (1979).

Em Santaella (2007. pág. 80) essa questão the propiciou a seguinte observação:

"Orozco Gomez esclarece que entender o jogo atual da mediação implica abandonar a idéia de que mediações vêm só de meios e são de certa maneira sua extensão. Contra esse reducionismo concebe as mediações como processos estruturantes que provêm de diversas fontes e incidem nos processos de comunicação, formando as interações comunicativas dos atores sociais, ao substituir a relevância que as mediações institucionais típicas do modernismo, tais como a escola e o Estado, desempenhavam para a produção de sentido junto ás audiências, a mediação tecnológica atinge hoje uma importância desmedida, influenciando as mediações cognitivas na medida em que as possibilidades tecnológicas de transmissão e consumo de informação e principalmente de imagens alteram a percepção, o que coloca a percepção no centro das transformações presentes e futuras, no âmbito da comunicação, cada vez mais estimulada pela mediação tecnológica". 
É nesse contexto que se destaca a perspectiva de compreensão denominada de "dupla mediação" entre técnica e sociedade, na acepção de Miège (2007, pág. 44 ). Não se limita esta perspectiva ao reconhecimento de que há mediações entre técnica e sociedade mas assinala-se em especial a busca da inter-relação então criada e que se manifesta no seu enraizamento, ou seja, no interior das práticas sociais. É no interior dessas práticas que o tecido social cotidianamente sendo construído e atualizado expressa o enraizamento de valores, ou na acepção de Heller (1972) sobre a vida cotidiana, é nesse espaço que se dá "a hierarquização da condução da vida".

A peculiaridade dessa proposição da "dupla mediação" está no fato de que ela é "ao mesmo tempo técnica pois a ferramenta utilizada estrutura a prática, mas a mediação é também social porque os motivos, as formas de uso e o sentido atribuído à prática se alimentam no corpo social" (Joüet, apud Miège, 2007, pág. 44).

A fundamentação dessa proposição pode ser sinalizada desde uma afirmação de Castoriadis e que, segundo Miège (2007. pag. 5) bem sustenta este olhar:

"Mas o conjunto técnico ele mesmo está privado de sentido, técnico ou qualquer que seja, se o separarmos do conjunto econômico e social..."

Esta perspectiva, ainda que aqui apenas apontada em seu eixo de sustentação, já vem sendo trabalhada em outras tradições de pesquisa sobre comunicação social e pode significar uma possibilidade inovadora no campo dos estudos sobre práticas de comunicação. Pode ser uma estratégia metodológica que possibilita apreender no movimento mais imediato das práticas de comunicação da vida cotidiana as sinalizações da relação mais estrutural de como técnica e sociedade se relacionam na contemporaneidade de suas próprias mudanças. $\mathrm{O}$ enraizamento social desse duplo processo de mediação se expressa no interior das práticas cotidianas. O lugar das mediações se visualiza não em si mesmas mas no seu resultante, nas práticas de vida, e que dão sentido estruturante ao tecido social. Assim, se há mediações que qualificam e distinguem a relação das pessoas e os media, estes também exercem papel de mediação diante do eixo básico que define a comunicação como sustentada na relação das pessoas e a sociedade, ou, as pessoas e a vida.

\section{Deslocamentos e rearticulações: a auto-recepção publicizada}

Se essas diferentes questões encontram eco no campo mais amplo da comunicação social, ainda que importe melhor qualifica-las, aqui se restringe ao levantamento de indicações a respeito no âmbito mais especifico da recepção mediática. 
Retome-se um pouco mais a análise de traços que marcaram os estudos da recepção mediática na tradição norteamericana. Esses estudos se consolidaram na análise das praticas derivadas das mídias massivas, numa relação direta com o uso e expansão do cinema, do rádio da televisão e da imprensa e que traduziam desde o século passado a experiência generalizada e até então inédita de um processo massivo de comunicação. Assumiu-se uma postura até hoje hegemônica de compreensão da recepção aos meios de comunicação como resultante de uma prévia e como que linear concepção de causa e determinação dos media na vida social, uma linearidade já por demais assinalada especialmente nas implicações apassivadoras que acarreta. Uma linearidade que tem sido marcada pela verticalidade da relação de seus atores, matriz dos interesses que relacionam essa verticalidade a objetivos de poder, matriz igualmente da racionalidade que marca a modernidade enquanto estruturada desde meios e fins e que está subentendida na denominação mesmo das ferramentas técnicas de comunicação como meios.

Atente-se: se os media foram instrumentalizados pelo sistema eles também atuaram como instrumentalizadores de fins buscados no comportamento do receptor/consumidor. A comunicação como processo de vínculos sociais se viu sitiada e engessada pelo lugar dos media em seu desenvolvimento e fundamentação (Sousa 1995, pag. 13).

O cuidado na condução critica desse processo não invalida apontar aspectos que na prática dão a marca da interrelação então criada entre técnica e sociedade através dos meios massivos de comunicação. A tradição de estudos sobre consumo, audiência e opinião pública, usos e impactos de media, estratégias de marketing e de relações públicas, tanto quanto inúmeras experiências de pesquisas aí desenvolvidas, entre outros exemplos, explicitam a preocupação em identificar o lugar das ferramentas e meios da comunicação na qualificação da própria comunicação resultante nos âmbitos da vida pessoal ou social, bem como no campo das organizações e das instituições sociais. Os modos interpretativos resultantes desse esforço ao apontarem o poder instrumental dos media em comportamentos pessoais e coletivos, tanto quanto na sua condução ideológica e de forma massiva, na verdade reproduziram no âmbito da comunicação a mesma racional de meios e fins que marca o sistema político e econômico que sustenta a modernidade capitalista. Nesse sentido, como já assinalado acima, o modelo epistemológico que define a comunicação estruturada desde o emissor buscando pela mensagem e pelo canal o acesso ao receptor não difere da racional que sustenta o próprio sistema sócio-economico enquanto produção mediada pela tecnologia em busca igualmente de efeitos no consumo.

A questão toma outra direção interpretativa diante da configuração contemporânea da comunicação sendo marcada pela conectividade ao mesmo tempo que pelo contexto valorativo da sociedade pós-moderna. Essa nova configuração talvez possa ser sintetizada na expressão de Ribeiro como uma emergente cultura tecno-científica marcada 
"pelos avanços tecnológicos que cada vez mais transformam nossas concepções sobre nossos corpos (cyborgs), nossas comunidades (virtuais) nossas formas de sociabilidades (copresença eletrônica) e obrigam a incluir novas problemáticas nas agendas políticas”' (2002, pág. 2).

Esse novo universo, também denominado de ciberespaço como também de realidade virtual, rompe paradigmas do tempo e do espaço marcados pela modernidade, rearticula identidades e fronteiras criando como que um mundo paralelo, agora estruturado em redes e ambientes mediados por computador. Retomando afirmações acima de Couchot e de Bruno vivencia-se todo um novo contexto e uma nova racionalidade na produção do pensamento, das expressões estéticas, nas formas de conduzir e direcionar a vida pessoal e coletiva.

Essas rupturas e novas fronteiras estão assinaladas desde uma afirmação precisa e sintética de Lemos (2006. pag. 53) sobre a cibercultura e que segundo ele

"... caracteriza-se por 'três leis' fundadoras: a liberação do pólo da emissão, o principio de conexão em rede e a reconfiguração de formatos midiáticos e práticas sociais... Sob o prisma de uma fenomenologia do social esse tripé (emissão, conexão, reconfiguração) tem como corolário uma mudança social na vivência do espaço e do tempo. O objetivo é compreender a cibercultura analisando alguns de seus fenômenos atuais:os blogs, os pod-casts, os sistemas "peer to peer", os softwares de fonte aberta e arte eletrônica."

As "três leis" configuram uma nova matriz relacionai entre os agentes técnicos e humanos da comunicação. Há todo um conjunto de rupturas com o modelo vertical de comunicação mediática com deslocamentos de agentes, seus papéis e mecanismos de interação, os suportes técnicos e seus potenciais, criando um modelo horizontal da comunicação. Há um outro nexo relacionai, uma outra lógica, com novas condições técnicas de manifestação das pessoas, dos conteúdos e produtos derivados desse mesmo nexo.

Questões diversas surgem para indagar sobre como então conceber o sujeito do processo comunicacional agora liberado do pólo emissor quando todo o processo que possibilita essa liberação está na dependência de dispositivos técnicos cooptados ao sistema mais amplo que os mantêm e disponibiliza, as bases do sistema capitalista. Questões outras indagam sobre a efetiva ruptura do controle, do rompimento quanto ao poder do sistema socioeconomico, em suas múltiplas formas, conteúdos e estratégias, liberando de fato o processo de conexão em rede tanto quanto conferindo autonomia a criatividade. Questões outras também assinalam a fragilidade da interatividade nesse processo.

Essas observações traduzem uma indagação de fundo, ou seja, se à maneira das tradições de estudo da comunicação vertical, estas não seriam novas manifestações da mediação sistêmica, agora no âmbito de um novo "tempo e do 
espaço", na pós-modernidade. A mediação dos valores da sociedade em mutação encontrariam eco e condições de alimentação exatamente nos valores que compartilha com os dispositivos da conectividade, uma dupla mediação estaria em curso: do lado da técnica, a libertação do polo emissor e conseqüente capacidade propositiva, criativa e argumentativa, e do lado do sistema social, em uma conexão que integra o indivíduo em redes e comunidades, atendendo uma das maiores limitações do homem contemporâneo, a busca de uma identidade cultural, de razões e formas do estar junto social. As tecnologias proveriam quando não substituiriam diferentes lacunas de interação social que o próprio contexto da sociedade em mutação não possibilita ou engessou através das instituições de base da organização social moderna. No contexto de mudanças que se dá na pós-modernidade a dimensão massiva da vida social estaria se manifestando agora na busca de identidades culturais arraigadas em individualidades ao mesmo tempo que em coletivos desterritorializados de noções de tempo e espaço. Blogs e vários outros fenômenos dessa nova articulação mediática atenderiam exatamente demandas crescentes da sociedade voltada para tribos e grupos relacionais e em configuração marcada pela vivência do tempo presente e não mais pelo tempo linear, como na modernidade.

Ainda que apoiando a argumentação da existência de estreito nexo que aproxima ciberespaço e posmodernidade, Lemos (2002, pág. 97) adverte que mesmo que cibernética signifique controle e pilotagem:

"a cibercultura não é o resultado linear e determinista de uma programação técnica e social. Ela parece ser, ao contrário, o resultado de uma apropriação simbólica e social da tecnologia. O que vai caracterizar a cibercultura nascente não é um determinismo tecnocrático. Não se trata de excluir a socialidade, e tudo o que ela tem de trágico, violento, erótico ou lúdico como inimiga de uma sociedade racional, técnica e objetiva. A cibercultura não é uma cibernetização da sociedade mas a tribalização da cibernética".

Destaque-se que talvez o eixo central de mudança nessa nova configuração da comunicação esteja na possibilidade que oferece de ser espaço não só para um "se inserir' ativo, mas para uma inserção publica, em um comum social.Um processo que estimula e provoca o se expressar, o se expor, o participar, o contestar, o informar de idéias e valores morais e estéticos, identidades em exposição e debates, e importante, de forma social-pública. Sociabilidade e publicização passam a se coñfundir tanto quanto a envolver as dimensões de autonomia e de direito de inserção nessa nova praça. Não se dá uma inserção técnica apenas, como na passagem de desconectado/conectado, mas através dela chegar a relações de estar junto, participar, pertencer ao que é comum sem ser necessariamente sob o signo do massivo ou do opressivo. É bem verdade que cabe indagar sobre o que constitui no tempo e no espaço da contemporaneidade esse comum buscado, a qualificação do que o caracteriza no histórico do sistema 
mais amplo que o envolve tanto quanto nas muitas e simultâneas perspectivas que imediatamente o expressam.

Castells é enfático ao caracterizar a importância do ciberespaço no surgimento de uma nova sociabilidade, de um sistema de relações sociais centrado no indivíduo. Admite que "o novo padrão de sociabilidade em nossas sociedades é caracterizado pelo individualismo em rede.” (2003, 108). As comunidades, retomadas hoje em seu termo mas deslocadas da concepção de espaço físico e de lugares, são dimensionadas segundo os espaços sociais que ocupam exercendo igualmente um poder de mediação entre os indivíduos e as redes de relacionamento.

Essa postura é polêmica pelas implicações de uma polarização por demais valorativa do poder da técnica sobre a individualidade. Flichy (2004) em instigante trabalho sobre o tema do individualismo conectado, aponta para a importância de se levar em conta as múltiplas mediações presentes nas relações entre tecnologias da comunicação e da informação e o que vem sendo criticamente denominado de "a sociedade do individualismo conectado", ou ainda, de "comunicação de massa individual".

A dupla mediação entre técnica e sociedade se expressaria nesse novo contexto segundo múltiplas mediações, com deslocamentos fundamentais em seu efeito-produto, ou seja, o enraizamento derivado não se volta mais para o fim consumo, como no modelo massivo, mas ainda que com o consumo e através dele busca algo além, chegar a um resultante na interatividade, nas possibilidades do que poderia ser denominado de uma efetiva chance de um estar junto realmente "publicado", ou "publicizado", a sociabilidade efetivada de fato. A estrutura de redes de socialização traz em si mesma a noção de que é uma socialização publicizada. A convivência cotidiana com media verticais e horizontais reforçariam a construção contemporânea de uma prática de socialização buscada, tomada pública e não apenas consentida ou derivada na exposição e uso de diferentes media. Tem expressão a afirmação de Levy (1994) de que "o espaço cibernético está na origem de uma nova arquitetura... de uma nova polis que está se constituindo”.

Já nos estudos sobre comunicação e sociedade desenvolvidos desde o século passado essa temática da publicização vem sendo trabalhada, se confundindo com os estudos sobre esfera pública e opinião pública.

Essas questões centralizadas na discussão do espaço social público, têm envolvido desde a década passada um grande fluxo de posições interpretativas e que se expressam ora sob a denominação de esfera pública política (Habermas), ora sob a característica de espaço de exposição e cena de argumentos (Gomes, 1998), espaço de visibilidade (Thompson, 1998), espaço que reproduz a diferença e a pluralidade da sociedade contemporânea, portanto um espaço público necessariamente de conflito, e por isso mesmo um espaço fragmentado (Miège, 1999), um espaço de concretização social do Sujeito-ator (Touraine, 
1995), um espaço de demandas coletivas e de possibilidades de um espaço público virtual. (Ribeiro, 2002; Maia, 2002).

Enfim, se as perspectivas interpretativas aqui sendo apontadas são válidas, há um conjunto de rearticulações surgindo: a recepção mediática, ainda que na manutenção desse termo, expressa um especial processo onde mais do que a busca das mediações que se interpõem entre as pessoas e os media, importa buscar o lugar dos media como mediação das pessoas diante da sociedade. Os media exercem o papel mediador de publicização da negociação entre os indivíduos e a sociedade, são mediadores de um espaço relacionai não apenas de consumo, mas de criação e produção sobretudo pela potencialidade do mundo virtual.

Nas práticas de vida cotidiana se expressaria agora uma outra e renovada prática de recepção mediática marcada pela identificação dos processos de construção e objetivação da subjetividade e de seu enraizamento no tecido social. Uma prática onde o receptor se coloca ao lado de todo um outro processo, como que ao mesmo tempo paralelo, próximo e convergente, marcado pelo seu poder interpretante e pelo seu papel de autonomização diante de si e da sociedade, do privado e do publico, do individual e do comum social. Seria a emergência de receptor ao mesmo tempo autônomo e por isso mesmo também autor, ou, um auto-receptor. Se retomadas as palavras de Levy (1994, pág. 2) ainda que em um outro contexto interpretativo, aqui tem sentido especial sua afirmação de que

"o leitor passa a participar da própria redação do texto à medida que ele não está mais na posição passiva diante de um texto estático, uma vez que ele tem diante de si não uma mensagem estática, mas um potencial de mensagem. Então, o espaço cibernético introduz a idéia de que toda leitura é uma escrita em potencial." 


\section{Bibliografia}

BELISLE, C. e outros. 1992. Medias, La reception revisitée. Rev. Media Pouvoirs. Paris, França, n. 25

BRUNO, F. 2003. Tecnologias cognitivas e espaços do pensamento. In: França, Vera e outros (orgs). Livro do XI Compós/2002/Estudos de comunicação; Porto Alegre, Ed. Sulina.

COUCHOT, E. 2003. A tecnologia na arte, da fotografia a realidade virtual. Porto Alegre. Ed. UFRGS.

CASTELLS, M. 2003. A galáxia da internet. Rio de Janeiro. Jorge ZAHAR Editor.

FLICHY, P. 2004. L'Individualism connecté entre la technique numerique et la societé. Revue Reseaux, n. 124. Paris, França.

GOMES, W 1998. Esfera pública, política e media: com Habermas, contra Habermas. In: Rubin, A. A. C. e outros (orgs). Produção e recepção dos sentidos mediáticos. Petrópolis. Compós/Ed.Vozes.

HABERMAS, J. 1984. Mudança estrutural da esfera pública. Rio de Janeiro. Biblioteca Tempo Brasileiro.

HEIDEGGER, M. 2002. Ensaios e conferencias. Petrópolis. Ed. Vozes.

HELLER, A. 1972. O cotidiano e a história. Rio de Janeiro, Ed. Paz e Terra.

LEMOS, A. 2002. Cibercultura, tecnologia e vida social na cultura contemporânea. Porto Alegre, Ed. Sulina.

LEMOS, A. 2006. Cibercultura-remix in Denize, C. A. (org). Imagem (ir)realidade cotidiana comunicação e cibermídia. Porto Alegre, Ed. Sulina.

LEVY, P. 1994. A emergência do cyberspace e as mutações culturais. Paper, Festival Usina de Arte e Cultura. Prefeitura Municipal de Porto Alegre.

MAIA, R, C. M. 2002. Democracia e a internet como esfera virtual: aproximação às condições de deliberação. In:

MOTTA, L. G. e outros (orgs). 2002. Estratégias e Culturas da Comunicação. Brasilia, Ed. Unb.

MARTÍN-BARBERO, J. 1995. América Latina e os anos recentes: o estudo da recepção em comunicação social. In SOUSA, M. W. (org). Sujeito o lado oculto do receptor. São Paulo, Ed. Brasiliense.

MARCONDES FILHO, Ciro. 1990. Comunicação Ano Zero. In: Rev. Comunicação e Política, São Paulo. Ano 9. n. 1. 
MIÈGE, B. 2007. La societè conquise par la communication. Grenoble. França. $P U G$.

MIÈGE, B. 1999. O espaço público: perpetuado, ampliado e fragmentado. Revista Novos Olhares. N. 3. CTR/ECA/USP. São Paulo.

RIBEIRO, G. L. 2002. El espacio publico virtual. Serie Antropologica, $n .318$ Departamento de Antroplogia. Brasília, Ed. UNB.

RÜDIGER, F. 2003. Introdução às teorias da cibercultura. Porto Alegre, Ed. Sulina.

RÜDIGER. F. 2006. Martin Heidegger e a questão da técnica. Porto Alegre, Ed. Sulina.

WILLIANS, R. 1979. Marxismo e Literatura. Rio de Janeiro. Zahar

SANTAELLA, L. 2007. Linguagens líquidas na era da mobilidade. São Paulo, Ed. Paulus.

THOMPSON. J. B. A mídia e a modernidade. Petrópolis. Ed. Vozes.

TOURAINE, A. 1995. Crítica da modernidade. Petrópolis. Ed. Vozes. 